\title{
Impaired Fibrinolytic Activity Is Present in Children with Dyslipidemias
}

\author{
MANUELA ALBISETTI, ANTHONY K.C. CHAN, BRIAN W. MCCRINDLE, DEREK WONG, \\ PAUL MONAGLE, AND MAUREEN ANDREW†
}

\begin{abstract}
Hamilton Civic Hospitals Research Centre, Hamilton, Ontario, Canada L8V 1 C3 [M.A., A.K.C.C., M.A.]; Division of Hematology/Oncology, The Hospital for Sick Children, Toronto, Ontario, Canada M5G 1 X8

[M.A.]; Division of Cardiology, The Hospital for Sick Children, Toronto, Ontario, Canada M5G 1X8 [B.W.M.,

D.W.]; and Division Laboratory Services, Royal Children's Hospital, Melbourne, 3052 Australia [P.M.].
\end{abstract}

\begin{abstract}
Dyslipidemias are major risk factors for atherosclerosis and cardiovascular disease. Abnormalities of fibrinolytic and coagulation components are considered useful predictors of cardiovascular morbidity and mortality in adults. This study examined whether fibrinolytic and coagulation components are abnormal in children with dyslipidemia. Thirty-six children with asymptomatic dyslipidemia, and 26 control subjects underwent venous occlusion stress testing with collection of preocclusion and postocclusion blood samples. All samples were assayed for tissue plasminogen activator, plasminogen, plasminogen activator inhibitor-1, $\alpha_{2}$-antiplasmin, $\alpha_{2}$-macroglobulin, D-dimer, fibrinogen, and von Willebrand factor. Children with dyslipidemia had significantly decreased levels of tissue plasminogen activator in both preocclusion and postocclusion samples compared with control subjects, reflecting decreased fibrinolytic activity. Children with dyslipidemia also had significantly increased levels of plasminogen, $\alpha_{2}$-macroglobulin, and fibrinogen in preocclusion and postocclusion samples compared with control subjects. In
\end{abstract}

\section{ABSTRACT}

conclusion, decreased fibrinolytic activity is present in asymptomatic children with dyslipidemias, potentially reflecting endothelial dysfunction and increased risk of cardiovascular disease in early adult life. Further studies are required to determine the usefulness of this marker in predicting disease progression or response to therapy. (Pediatr Res 55: 576-580, 2004)

DL, dyslipidemia
tPA, tissue plasminogen activator
PAI, plasminogen activator inhibitor
vWF, von Willebrand factor
VO, venous occlusion
$\boldsymbol{\alpha}_{\mathbf{2}}-\mathbf{A P}, \alpha_{2}$-antiplasmin
$\boldsymbol{\alpha}_{\mathbf{2}}-\mathbf{M}, \alpha_{2}$-macroglobulin
CI, confidence interval
TC, total cholesterol

DL defines abnormalities in the lipid profile caused by both genetic and acquired metabolic disorders. Most of the genetic lipid disorders are dominantly inherited and include familial hypercholesterolemia, familial combined hyperlipidemia, familial hypertriglyceridemia, and familial hypoalphalipoproteinemia (1). Acquired abnormalities in lipid metabolism are most commonly related to obesity (2). Persistent abnormalities of the lipid profile during childhood are associated with accel-

Received April 22, 2003; accepted August 11, 2003.

Correspondence: Manuela Albisetti, M.D., University Children's Hospital, Steinwiesstrasse 75, CH-8032 Zürich, Switzerland; e-mail: manuela.albisetti@kispi.unizh.ch

Supported by a grant from the Heart and Stroke Foundation of Canada. M. Andrew was a Career Investigator of the Heart and Stroke Foundation of Canada. M. Albisetti is the recipient of a Stipendium zur Foerderung des Akademischen Nachwuchses of the University of Zurich, Switzerland. A.K.C. Chan is a recipient of the Research Scholarship from the Heart and Stroke Foundation of Canada. P. Monagle is supported by a research fellowship from the Murdoch Children's Research Institute.

$\dagger$ Deceased.

DOI: 10.1203/01.PDR.0000112098.64368.8A erated atherosclerosis and increased cardiovascular risk in early adult life (3).

Atherosclerosis is a chronic inflammatory response of the endothelium to metabolic and physical injuries leading to gradual accumulation of plaque in the vessel wall (4). The pathogenesis of atherosclerosis begins during childhood with the appearance of intimal lesions in the aorta of young children and fatty streaks in coronary arteries of adolescents. These lesions occur at the same vascular sites of atherosclerotic plaques observed in older ages (5-7). The process of atherogenesis leads to abnormal endothelial cell function that can be detected in the early stages, before anatomic evidence of plaque formation occurs $(4,8)$.

Studies in asymptomatic adults at risk for future myocardial infarction suggest that increased baseline plasma concentrations of tPA and PAI-1, reflecting reduced fibrinolytic activity, and increased plasma concentrations of fibrinogen or vWF are sensitive (nonspecific) markers of endothelial cell dysfunction, and useful predictors of future cardiovascular morbidity and mortality (9-17). 
The present study investigated whether abnormalities in plasma concentrations of components of the fibrinolytic or coagulation systems are present in children with DL.

\section{METHODS}

Patient population. All consecutive children with DL attending a follow-up clinic at the Hospital for Sick Children, Toronto, Ontario, Canada, and who were at least 8 y of age were considered for inclusion in this study. Age-matched healthy children on no medication and attending a school in Oakville, Ontario, Canada, were also asked to participate as a control group. Before entry into the study, informed consent was obtained from both the children and their parents. The study was approved by the research ethics boards of the Hospital for Sick Children and the Children's Hospital at McMaster University, Hamilton, Ontario, Canada.

Blood sampling. All blood samples were collected before and after VO by clean venepuncture from the antecubital fossa between 0800 and $1000 \mathrm{~h}$ after overnight fasting. Preocclusion blood samples were obtained from one arm without the use of a tourniquet and after $15 \mathrm{~min}$ of resting supine. VO was performed on the other arm using a sphygmomanometer inflated to mid-diastolic-systolic blood pressure for $10 \mathrm{~min}$. Postocclusion samples were obtained from the occluded arm before deflation of the blood pressure cuff. Blood samples were collected into $0.105 \mathrm{M}$ buffered trisodium citrate ( 9 parts blood:1 part citrate) for tPA antigenic assay, PAI-1 antigenic and activity assays, plasminogen antigen and activity assays, $\alpha_{2}$-AP, D-dimer, $\alpha_{2}$-M, fibrinogen, and vWF. Another sample was collected into acidified sodium citrate tubes $(\mathrm{pH} 4.3$; Stabilyte tubes; American Diagnostica, Greenwich, CT, USA) for tPA activity assays. All blood samples were centrifuged at $1700 \times \mathrm{g}$ for $15 \mathrm{~min}$ at $4^{\circ} \mathrm{C}$ within $20 \mathrm{~min}$ of collection, and platelet-poor plasma was aliquoted and frozen at $-70^{\circ} \mathrm{C}$ until time of assay. All postocclusion results were corrected for hemoconcentration using the correction factor $F$, calculated as follows:

$$
F=\mathrm{HCT}_{1} \times\left(1-0.9 \times \mathrm{HCT}_{2}\right) / \mathrm{HCT}_{2} \times\left(1-0.9 \times \mathrm{HCT}_{1}\right)
$$

where $\mathrm{HCT}_{1}$ and $\mathrm{HCT}_{2}$ are hematocrit values before and after $\mathrm{VO}$, respectively (18).

Laboratory assays. The following assays were performed following the manufacturer's guidelines: tPA antigen (Imubind, tPA; American Diagnostica), tPA activity (Spectrolyse tPA/PAI; American Diagnostica), PAI-1 antigen (Imubind, PAI-1; American Diagnostica), PAI-1 activity (Spectrolyse PAI-1; American Diagnostica), plasminogen antigen (Imuclone; American Diagnostica), plasminogen activity (Actichrome PLG; American Diagnostica), and $\alpha_{2}$-AP activity (Actichrome; American Diagnostica) using an automated coagulation laboratory (ACL 300; Milan, Italy); D-dimer (Dimertest Gold EIA; American Diagnostica); fibrinogen by semiautomated Clauss method (ST4; Diagnostica Stago, Asnières, France); vWF antigen by ELISA (Affinity Biologicals, Hamilton, Ontario, Canada); and $\alpha_{2}-\mathrm{M}$ antigen immunologically by radial immunodiffusion using commercially avail- able antibody (Cedarlane, Laboratories Limited, Hornby, Ontario, Canada).

Hematocrits were measured on a Coulter STK-S (Coulter Canada, Burlington, ON, Canada). The lipid profile including TC, HDL cholesterol, LDL cholesterol, and triglycerides was measured on a Vitros 950 Chemistry System (Ortho Clinical Diagnostics Inc, Rochester, NY, USA).

Statistical analysis. Plasma concentrations of components of the fibrinolytic and coagulation system of preocclusion and postocclusion samples are presented as mean $\pm 95 \% \mathrm{CI}$. Ninety-five percent CI were calculated from SEM, assuming symmetric distribution of all the fibrinolytic and coagulation variables measured. To evaluate the interrelationship between the amount of the free active fraction of TPA (tPA activity) and the total IPA (tPA antigen), consisting of both the free active and the complexed inactive fraction of tPA, tPA activity/tPA antigen ratios in patients and control subjects were calculated and results presented as mean $( \pm 95 \% \mathrm{CI})$. From previous published studies in adults, results of tPA and PAI-1 were considered the primary outcomes. Results of the other fibrinolytic and coagulation components were considered secondary outcomes. Statistically significant differences of mean values of fibrinolytic and coagulation components between patients and control subjects were tested by two-tailed $t$ test. To assess whether fibrinolytic and coagulation components varied between children with familial DL and children with obesityrelated DL as well as between children with hypercholesterolemia and children with hypertriglyceridemia, significant differences of mean values were assessed by one-way ANOVA with post hoc comparisons (Tukey-Kramer multiple comparisons test). Probability values less than 0.05 were considered statistically significant.

\section{RESULTS}

Patient population. Thirty-six children with DL (14 girls and 22 boys) aged 8 to $16 \mathrm{y}$ (mean, $12.5 \mathrm{y}$; median, $12.4 \mathrm{y}$ ) were included in this study. Twenty-three children had familial hypercholesterolemia, four children had familial combined hyperlipidemia, and nine children had obesity-related hyperlipidemia with a mean body mass index of 29.6. Results of the lipid profile and the calculated TC/HDL and LDL/HDL ratios are presented in Table $1(19,20)$. At the time of the study three children were receiving oral antihypercholesterolemic therapy with colestipol. All children had normal blood pressures. Twentysix healthy children (14 girls, and 12 boys), aged 13 to 18 y (mean and median, $16 \mathrm{y}$ ), were included as control subjects.

Table 1. Lipid profile of children with $D L$

\begin{tabular}{lcc}
\hline & Children with DL & $\begin{array}{c}\text { Pediatric } \\
\text { reference range* }\end{array}$ \\
\hline TC (mM) & $6.81(6.07-7.54)$ & $3.20-4.40$ \\
HDL-cholesterol $(\mathrm{mM})$ & $1.06(0.96-1.16)$ & $0.96-1.91$ \\
LDL-cholesterol $(\mathrm{mM})$ & $4.99(4.24-5.73)$ & $1.66-3.41$ \\
Triglycerides $(\mathrm{mM})$ & $1.71(1.38-2.03)$ & $0.40-1.30$ \\
TC/HDL ratio & $7.22(5.73-8.71)$ & $<3.5$ \\
LDL/HDL ratio & $5.38(3.99-6.76)$ & $<3.0$ \\
\hline
\end{tabular}

Data are reported as mean $(95 \% \mathrm{CI})$.

$*[19,20]$. 
Preocclusion results of components of the fibrinolytic and coagulation system. Overall mean plasma concentrations ( \pm 95\% CI) of components of the fibrinolytic and the coagulation systems in preocclusion samples in patients and control subjects are summarized in Table 2. Mean plasma concentrations of tPA activity were significantly decreased in patients compared with control subjects, whereas mean tPA antigen plasma concentrations were similar in both populations (Table 2). Patients also showed significantly increased plasma concentrations of plasminogen (antigen and activity) and $\alpha_{2}$-M relative to control subjects, as well as highly significantly increased plasma concentrations of fibrinogen compared with control subjects (Table 2).

Compared with patients with familial DL, patients with obesity-related DL showed increased plasma concentrations of fibrinogen (mean, $3.73 \mathrm{~g} / \mathrm{L} ; 95 \% \mathrm{CI}, 3.14$ to $4.32 \mathrm{~g} / \mathrm{L}$ versus mean, $3.11 \mathrm{~g} / \mathrm{L} ; 95 \% \mathrm{CI}, 2.85$ to $3.373 \mathrm{~g} / \mathrm{L} ; p<0.05)$. Compared with patients with hypercholesterolemia, patients with hypertriglyceridemia showed increased plasma concentrations of both tPA antigen (mean, $7.29 \mathrm{ng} / \mathrm{mL} ; 95 \% \mathrm{CI}, 5.50$ to $9.07 \mathrm{ng} / \mathrm{mL}$ versus mean, $4.78 \mathrm{ng} / \mathrm{mL}$; $95 \% \mathrm{CI}$, 4.07 to 5.49 $\mathrm{ng} / \mathrm{mL}$ ) and plasminogen activity (mean, $1.45 \mathrm{U} / \mathrm{mL} ; 95 \% \mathrm{CI}$, 1.19 to $1.71 \mathrm{U} / \mathrm{mL}$ versus mean, $1.24 \mathrm{U} / \mathrm{mL} ; 95 \% \mathrm{CI}, 1.2$ to $1.28 \mathrm{U} / \mathrm{mL} ; p<0.05)$.

In all patients, plasma concentrations of components of the fibrinolytic and the coagulation systems in preocclusion samples showed no linear correlation with the results of the different lipid classes.

Postocclusion results of components of the fibrinolytic and coagulation system. Overall mean plasma concentrations ( \pm $95 \% \mathrm{CI}$ ) of components of the fibrinolytic and the coagulation systems in postocclusion samples in patients and control subjects are summarized in Table 3. Mean plasma concentrations of tPA antigen were significantly decreased in patients relative to control subjects (Table 3 ). Patients also showed significantly increased plasma concentrations of plasminogen (antigen and activity), and $\alpha_{2}-\mathrm{M}$ relative to control subjects, as well as highly significant increased plasma concentrations of fibrinogen (Table 3).

Compared with patients with familial DL, patients with obesity-related DL showed decreased plasma concentrations of

Table 2. Preocclusion results of fibrinolytic and coagulation components

\begin{tabular}{lccc}
\hline \multicolumn{1}{c}{ Variable } & DL & Control & $p$ value \\
\hline Fibrinolytic components & & & \\
tPA antigen $(\mathrm{ng} / \mathrm{mL})$ & $5.50(0.74)$ & $5.35(1.26)$ & $\mathrm{NS}$ \\
tPA activity $(\mathrm{U} / \mathrm{mL})$ & $1.29(0.26)$ & $1.89(0.52)$ & 0.03 \\
Plasminogen antigen $(\mu \mathrm{g} / \mathrm{mL})$ & $0.33(0.02)$ & $0.24(0.02)$ & $<0.00001$ \\
Plasminogen activity $(\mathrm{U} / \mathrm{mL})$ & $1.31(0.06)$ & $1.10(0.06)$ & 0.0007 \\
PAI-1 antigen $(\mathrm{ng} / \mathrm{mL})$ & $53.61(28.02)$ & $24.16(6.74)$ & $\mathrm{NS}$ \\
PAI-1 activity $(\mathrm{U} / \mathrm{mL})$ & $12.56(2.84)$ & $11.92(3.70)$ & $\mathrm{NS}$ \\
$\alpha_{2}-\mathrm{AP}(\mathrm{U} / \mathrm{mL})$ & $0.97(0.04)$ & $1.02(0.04)$ & $\mathrm{NS}$ \\
$\alpha_{2}-\mathrm{M}(\mathrm{U} / \mathrm{mL})$ & $1.51(0.10)$ & $1.27(0.08)$ & 0.004 \\
D-dimer $(\mathrm{ng} / \mathrm{mL})$ & $27.38(8.88)$ & $25.20(5.04)$ & $\mathrm{NS}$ \\
Coagulation components & & & \\
Fibrinogen $(\mathrm{g} / \mathrm{L})$ & $3.27(0.22)$ & $2.34(0.10)$ & $<0.00001$ \\
vWF $(\mathrm{U} / \mathrm{mL})$ & $1.21(0.12)$ & $1.22(0.18)$ & $\mathrm{NS}$ \\
\hline
\end{tabular}

Data are reported as mean $( \pm 95 \% \mathrm{CI})$.
Table 3. Postocclusion results of fibrinolytic and coagulation components

\begin{tabular}{lccc}
\hline \multicolumn{1}{c}{ Variable } & DL & Control & $p$ value \\
\hline Fibrinolytic components & & & \\
tPA antigen $(\mathrm{ng} / \mathrm{mL})$ & $7.62(1.28)$ & $9.91(1.56)$ & 0.02 \\
tPA activity $(\mathrm{U} / \mathrm{mL})$ & $1.66(0.34)$ & $2.08(0.34)$ & $\mathrm{NS}$ \\
Plasminogen antigen $(\mu \mathrm{g} / \mathrm{mL})$ & $0.31(0.02)$ & $0.20(0.01)$ & $<0.00001$ \\
Plasminogen activity $(\mathrm{U} / \mathrm{mL})$ & $1.25(0.08)$ & $1.06(0.10)$ & 0.006 \\
PAI-1 antigen $(\mathrm{ng} / \mathrm{mL})$ & $53.40(29.86)$ & $24.02(7.84)$ & $\mathrm{NS}$ \\
PAI-1 activity $(\mathrm{U} / \mathrm{mL})$ & $11.48(2.48)$ & $9.43(2.90)$ & $\mathrm{NS}$ \\
$\alpha_{2}-\mathrm{AP}(\mathrm{U} / \mathrm{mL})$ & $0.96(0.04)$ & $0.93(0.06)$ & $\mathrm{NS}$ \\
$\alpha_{2}-\mathrm{M}(\mathrm{U} / \mathrm{mL})$ & $1.41(0.08)$ & $1.20(0.08)$ & 0.004 \\
D-dimer $(\mathrm{ng} / \mathrm{mL})$ & $22.02(6.60)$ & $17.30(4.04)$ & $\mathrm{NS}$ \\
Coagulation components & & & \\
Fibrinogen $(\mathrm{g} / \mathrm{L})$ & $2.95(0.18)$ & $2.16(0.14)$ & $<0.00001$ \\
vWF $(\mathrm{U} / \mathrm{mL})$ & $1.12(0.08)$ & $1.14(0.16)$ & $\mathrm{NS}$ \\
\hline
\end{tabular}

Data are reported as mean $( \pm 95 \% \mathrm{CI})$.

tPA activity (mean, $0.92 \mathrm{U} / \mathrm{mL} ; 95 \% \mathrm{CI}, 0.48$ to $1.37 \mathrm{U} / \mathrm{mL}$ versus mean, $1.91 \mathrm{U} / \mathrm{mL} ; 95 \% \mathrm{CI}, 1.49$ to $2.33 \mathrm{U} / \mathrm{mL} ; p<$ $0.05)$ and increased plasma concentrations of both plasminogen antigen (mean, $0.34 \mu \mathrm{g} / \mathrm{mL} ; 95 \% \mathrm{CI}, 0.27$ to $0.41 \mu \mathrm{g} / \mathrm{mL}$ versus mean, $0.29 \mu \mathrm{g} / \mathrm{mL} ; 95 \% \mathrm{CI}, 0.27$ to $0.31 \mu \mathrm{g} / \mathrm{mL} ; p<$ 0.05 ) and PAI-1 activity (mean, $18.51 \mathrm{U} / \mathrm{mL} ; 95 \% \mathrm{CI}, 11.30$ to $25.72 \mathrm{U} / \mathrm{mL}$ versus mean, $9.44 \mathrm{U} / \mathrm{mL} ; 95 \% \mathrm{CI}, 7.39$ to 11.48 $\mathrm{U} / \mathrm{mL} ; p<0.01)$. No statistically significant differences in the plasma concentrations of all fibrinolytic and coagulation components measured were observed between patients with hypercholesterolemia and those with hypertriglyceridemia.

In all patients, plasma concentrations of components of the fibrinolytic and the coagulation systems in postocclusion samples showed no linear correlation with the results of the different lipid classes.

tPA activity/tPA antigen ratios. The mean $\mathrm{PA}$ activity/tPA antigen ratio was significantly decreased in patients (mean, $0.28 ; 95 \% \mathrm{CI}, 0.21$ to 0.33 ) relative to control subjects (mean, 0.43 ; $95 \% \mathrm{CI}, 0.30$ to $0.56 ; p=0.02$ ) in preocclusion samples, reflecting increased levels of inactive tPA relative to free tPA in children with DL compared with control subjects (Fig. 1). In postocclusion samples, mean tPA activity/tPA antigen ratios were no longer statistically different between patients (mean, $0.30 ; 95 \%$ CI, 0.15 to 0.43 ) and control subjects (mean, 0.24 ; $95 \% \mathrm{CI}, 0.19$ to $0.29 ; p=0.55$; Fig. 1 ). When compared with preocclusion ratios, tPA activity/tPA antigen ratios in postocclusion samples were unchanged in patients, but significantly decreased in control subjects $(p=0.01)$, suggesting a decreased fibrinolytic response to VO in children with DL compared with control subjects (Fig. 1).

No statistically significant differences in tPA activity/tPA antigen ratios were observed between patients with familial DL and patients with obesity-related DL as well as between patients with hypercholesterolemia and those with hypertriglyceridemia.

\section{DISCUSSION}

Dyslipidemias are major risk factors for the development of atherosclerotic heart disease in young adults. Epidemiologic data in adults suggest that impaired fibrinolysis is a sensitive (nonspecific) marker of endothelial dysfunction and a strong predictor of future cardiovascular disease (9-13). Although increased serum 


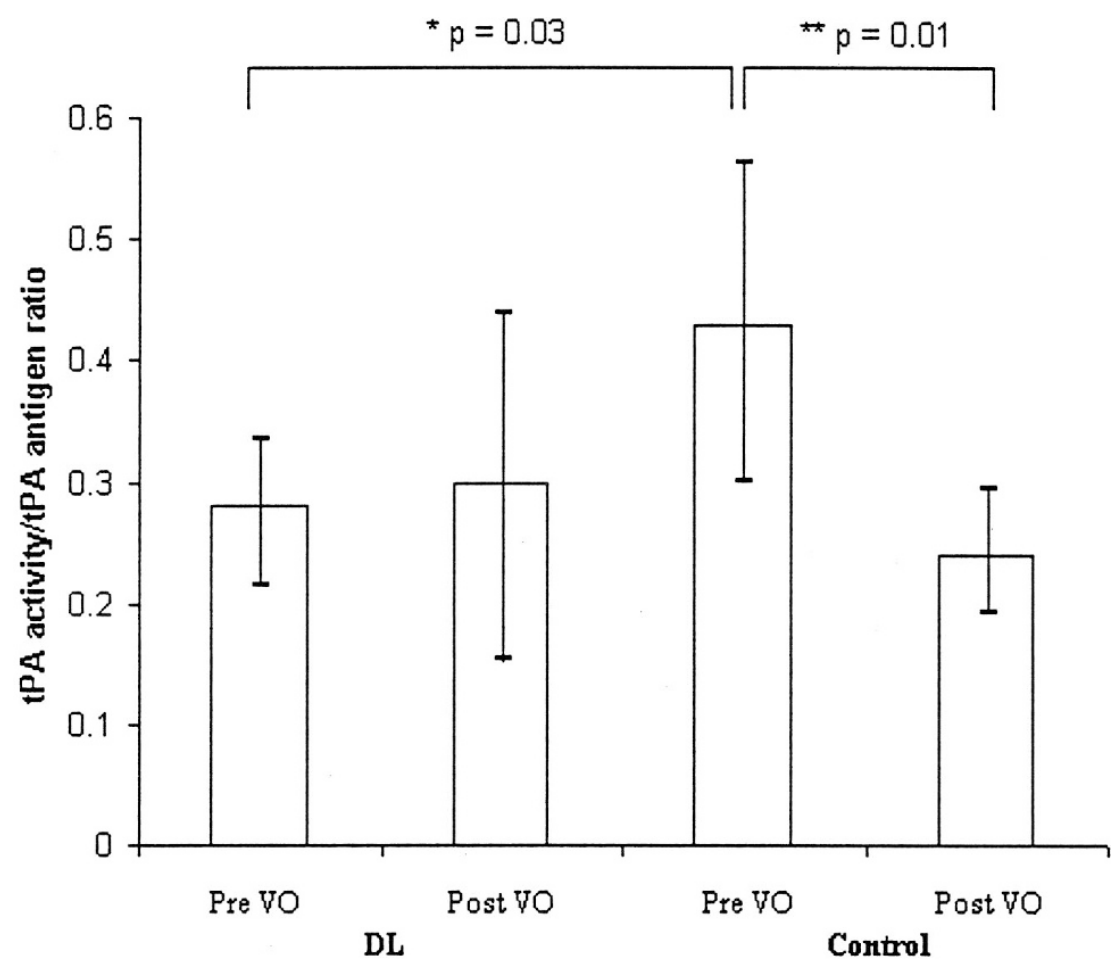

Figure 1. tPA activity/tPA antigen ratios of preocclusion (Pre VO) and postocclusion (Post VO) samples in patients with DL and control subjects. Data are shown as mean (bar) $\pm 95 \%$ confidence intervals (vertical lines). ${ }^{*} p$ value indicating a significant difference in tPA activity/tPA antigen ratios of preocclusion samples between patients and control subjects. ${ }^{* *} p$ value indicating a significant difference in tPA activity/tPA antigen ratios between preocclusion and postocclusion samples in control subjects.

lipid levels are readily identified in children with DL, no previous studies have determined whether impaired fibrinolysis commences during childhood. Results of this study show a reduced fibrinolytic activity in asymptomatic children with DL, suggesting that progressive endothelial dysfunction may occur early, which may justify early pharmacologic intervention in these children.

Normal serum lipid and lipoprotein levels differ markedly in children to adults, and age-specific ranges are welldocumented (21). There is considerable evidence that hypercholesterolemic adults have abnormal lipid levels in childhood $(22,23)$. Family screening is frequently performed to detect affected children in the belief that early intervention will be of benefit, although the age at which intervention should be optimally initiated remains unknown.

Impaired flow-mediated dilation of femoral and brachial arteries reflecting endothelial dysfunction can be demonstrated in children with familial DL as young as 8 y of age $(8,24,25)$. In addition, $66 \%$ of asymptomatic teenagers with heterozygous familial hypercholesterolemia and positive family history have abnormal cardiac stress thallium scans (26). Stress thallium scans have also been shown to highly correlate with angiographic abnormalities in homozygous familial hypercholesterolemia (27).

Although decreased fibrinolytic activity is considered a useful predictor of endothelial dysfunction in adults with atherosclerosis (10-13), there is still some controversy about whether decreased fibrinolytic activity is a consequence or a primary process in the pathophysiology of endothelial dysfunction. Abnormalities of the fibrinolytic system have not previously been investigated in children with DL. Major components of the fibrinolytic system, including tPA and, in part, PAI-1, are produced and released by endothelial cells (28). VO stress testing is a sensitive measure of the fibrinolytic system, measuring both the baseline (preocclusion) and endothelialstimulated (postocclusion) fibrinolytic potential (29).

Our results show decreased fibrinolytic activity in asymptomatic children with DL before and after VO. Two different mechanisms responsible for the impaired fibrinolytic activity could be identified. Before VO, decreased fibrinolytic activity was related to decreased tPA activity in conjunction with a relative increase of complexed inactive tPA relative to free active tPA and to increased plasma concentration of $\alpha_{2}-\mathrm{M}$. Although plasma concentrations of tPA antigen have been shown to reflect an inhibitory effect of PAI-1 on tPA activity, tPA complexes are not only formed with PAI-1 but also with other minor inhibitors including $\alpha_{2}-\mathrm{M}(11,30,31)$. Because plasma concentrations of PAI-1 antigen and activity were similar in both populations, the finding of increased plasma concentrations of $\alpha_{2}-\mathrm{M}$ in our patients suggests the presence of an increased inhibitory effect of this proteinase inhibitor on tPA. After VO, decreased fibrinolytic activity was related to decreased plasma concentration of tPA antigen. Impaired fibrinolytic response to $\mathrm{VO}$ has been related to either a deficient release of tPA during VO or increased PAI-1 activity levels before VO $(32,33)$. Because plasma concentrations of PAI-1 antigen and activity were similar in both populations, and no increased residual PAI-1 activity was present in patients relative to control subjects, impaired fibrinolytic response to $\mathrm{VO}$ in our patients likely reflects impaired release of tPA from the vascular endothelial cells, suggesting the presence of endothelial cell damage. 
In our study, patients with obesity-related DL showed significantly decreased plasma concentrations of tPA activity and increased plasma concentrations of PAI-1 activity after VO compared with patients with familial DL. Although these findings suggest that the different types of DL may be associated with different degrees of severity of endothelial dysfunction and hypofibrinolysis, the number of patients in this study does not allow definite conclusions to be made.

Our results also show increased plasma concentrations of plasminogen, fibrinogen, and $\alpha_{2}-\mathrm{M}$ in children with DL. $\alpha_{2}-\mathrm{M}$ is a major plasma proteinase inhibitor that acts as a molecular trap for proteinase molecules including factor Xa, thrombin, tPA, kallikrein, and plasmin, hindering their ability to react with other proteins $(31,34-36)$. Increased concentrations of plasminogen and fibrinogen may reflect increased inhibitory effect of $\alpha_{2}-\mathrm{M}$ not only on tPA, as described previously, but also on kallikrein as well as on factor $\mathrm{Xa}$ and thrombin, respectively. Thus, $\alpha_{2}-\mathrm{M}$ may play a role in decreasing the fibrinolytic activity in children with DL and may be a useful marker of endothelial cell dysfunction in patients at increased risk for arterial disease. Further study is required to clarify the extent to which $\alpha_{2}$-M inhibits the fibrinolytic system relative to the coagulation system in these patients.

\section{CONCLUSIONS}

In summary, a decreased fibrinolytic activity is present in children with DL, suggesting the presence of endothelial cell dysfunction and possible early presymptomatic atherosclerosis. Further studies are required to determine possible cutoff values of fibrinolytic and coagulation components as useful indicators of both disease progression and response to therapy in children with DL, and whether the age of onset of fibrinolytic abnormalities predicts severity of future cardiovascular disease.

Acknowledgments. During the preparation of this manuscript, the senior author, Dr. Maureen Andrew, passed away. Dr. Andrew was responsible for the design of the project, and integrally involved in analysis of the data and preparation of the manuscript. We dedicate this work to her memory.

The authors thank M. Adams, M. Dinyari, and P. Vegh for research assistance and technical support, and American Diagnostica, Greenwich, CT, USA, for supplying the kits used for assays.

\section{REFERENCES}

1. Baker AL, Roberts C, Gothing C 1995 Dyslipidemias in childhood. Nurs Clin North Am 30:243-258

2. McCrindle BW 2000 Screening and management of hyperlipidemia in children. Pediatr Ann 29:500-508

3. Bao W, Srinivasan SR, Wattigney WA, Bao W, Berenson GS 1996 Usefulness of childhood low-density lipoprotein cholesterol level in predicting adult dyslipidemia and other cardiovascular risks. The Bongalusa Heart Study. Arch Intern Med $156: 1315-1320$

4. Celermajer DS 1997 Endothelial dysfunction: does it matter? Is it reversible? J Am Coll Cardiol 30:325-333

5. Stary HC 1990 The sequence of cell and matrix changes in atherosclerotic lesions of coronary arteries in the first forty years of life. Eur Heart J 11(suppl E):3-19

6. Berenson GS, Srinivasan SR, Bao W, Newman 3rd WP, Tracy RE, Wattigney WA 1998 Association between multiple cardiovascular risk factors and atherosclerosis in children and young adults. N Engl J Med 338:1650-1656

7. Napoli C, Glass CK, Witztum JL, Deutsch R, D’Armiento FP, Palinski W 1999 Influence of maternal hypercholesterolaemia during pregnancy on progression of early atherosclerotic lesions in childhood: fate of early lesions in children (FELIC) study. Lancet 354:1234-1241

8. Celermajer DS, Sorensen KE, Gooch VM, Spiegelhalter DJ, Miller OI, Sullivan ID 1992 Non-invasive detection of endothelial dysfunction in children and adults at risk of atherosclerosis. Lancet 340:1111-1115

9. Ridker PM, Vaughan DE, Stampfer MJ, Manson JE, Hennekens CH 1993 Endogenous tissue-type plasminogen activator and risk of myocardial infarction. Lancet 341:1165-1168

10. Jansson JH, Olofsson BO, Nilsson TK 1993 Predictive value of tissue plasminogen activator mass concentration on long-term mortality in patients with coronary artery disease. Circulation 88:2030-2034

11. Cortellaro M, Cofrancesco E, Boschetti C, Mussoni L, Donati MB, Cardillo M, Catalano M, Gabrielli L, Lombardi B, Specchia G, Tavazzi L, Tremoli E, Pozzoli E, Turri M, for the PLAT Group 1993 Increased fibrin turnover and high PAI-1 activity as predictors of ischemic events in atherosclerotic patients. Arterioscler Thromb 13:1412-1417

12. Juhan-Vague I, Pyke SD, Alessi MC, Jespersen J, Haverkate F, Thompson SG 1996 Fibrinolytic factors and the risk of myocardial infarction or sudden death in patients with angina pectoris. Circulation 94:2057-2063

13. Thompson SG, Kienast J, Pyke SD, Haverkate F, van de Loo JC 1995 Hemostatic factors and the risk of myocardial infarction or sudden death in patients with angina pectoris. N Engl J Med 332:635-641

14. Levenson J, Giral P, Razavian M, Gariepy J, Simon A 1995 Fibrinogen and silent atherosclerosis in subjects with cardiovascular risk factors. Arterioscler Thromb Vasc Biol 15:1263-1268

15. Ernst E, Resch KL 1993 Fibrinogen as a cardiovascular risk factor: a meta-analysis and review of the literature. Ann Intern Med 118:956-963

16. Benderly M, Graf E, Reicher-Reiss H, Behar S, Brunner D, Goldbourt U 1996 Fibrinogen is a predictor of mortality in coronary heart disease patients. Arterioscler Thromb Vasc Biol 16:51-56

17. Jansson JH, Nilsson TK, Johnson O 1991 von Willebrand factor in plasma: a novel risk factor for recurrent myocardial infarction and death. Br Heart J 66:351-355

18. Keber D 1983 On the use of different correction factors for haemoconcentration. Thromb Haemost 49:245

19. Dinwoodie A, Frohlich J, Hoag G, Luxton AW, McQueen M, Rasaiah B, Salkie ML 1989 Position of the CSCC and CAP Task Force on the assessment of risk of CHD. Clin Biochem 22:231-237

20. Tamir I, Heiss G, Glueck CJ, Christensen B, Kwiterovich P, Rifkind BM 1981 Lipid and lipoprotein distributions in white children ages 6-19 yr. The Lipid Research Clinics Programs Prevalence Study. J Chronic Dis 34:27-39

21. Haber C, Kwiterovich PO 1984 Dyslipoproteinemia and xanthomatosis. Pediatr Dermatol 1:261-280

22. West RJ, Lloyd JK 1979 Hypercholesterolemia in childhood. Adv Pediatr 26:1-34

23. Fallat RW, Tsang RC, Glueck CJ 1974 Hypercholesterolemia and hypertriglyceridemia in children. Prev Med 3:390-405

24. Sorensen KE, Celermajer DS, Georgakopoulos D, Hatcher G, Betteridge DJ, Deanfield JE 1994 Impairment of endothelium-dependent dilation is an early event in children with familial hypercholesterolemia and is related to the lipoprotein(a) level. $\mathrm{J}$ Clin Invest 93:50-55

25. Clarkson P, Celermajer DS, Powe AJ, Donald AE, Henry RM, Deanfield JE 1997 Endothelium-dependent dilatation is impaired in young healthy subjects with a family history of premature coronary disease. Circulation 96:3378-3383

26. Hegele RA, Connelly PW, Cullen-Dean G, Rose V 1993 Elevated plasma lipoprotein(a) associated with abnormal stress thallium scans in children with familial hypercholesterolemia. Am J Cardiol 72:402-406

27. Mouratidis B, Vaughan-Neil EF, Gilday DL, Ash JM, Cullen-Dean G, McIntyre S, MacMillan JH, Rose V 1992 Detection of silent coronary artery disease in adolescents and young adults with familial hypercholesterolemia by single-photon emission computed tomography thallium-201 scanning. Am J Cardiol 70:1109-1112

28. Van Hinsbergh VW, Kooistra T, Emeis JJ, Koolwijk P 1991 Regulation of plasminogen activator production by endothelial cells: role in fibrinolysis and local proteolysis. Int J Radiat Biol 60:261-272

29. Jennings I, Luddington RJ, Harper PI 1991 Changes in endothelial-related coagulation proteins in response to venous occlusion. Thromb Haemost 65:374-376

30. Nilsson TK 1989 Analysis of factors affecting tissue plasminogen activator activity and antigen concentration before and after venous occlusion in 123 patients. Clin Chem Enzymol Commun 1:335-341

31. Bennett B, Croll A, Ferguson K, Booth NA 1990 Complexing of tissue plasminogen activator with PAI-1, $\alpha_{2}$-macroglobulin, and C1-inhibitor: studies in patients with defibrination and a fibrinolytic state after electroshock or complicated labor. Blood 75:671-676

32. Nilsson IM, Ljungner H, Tengborn L 1985 Two different mechanisms in patients with venous thrombosis and defective fibrinolysis: low concentration of plasminogen activator or increased concentration of plasminogen activator inhibitor. BMJ 290:1453-1456

33. Nguyen G, Horellou MH, Kruithof EK, Conard J, Samama MM 1988 Residual plasminogen activator inhibitor activity after venous stasis as a criterion for hypofibrinolysis: a study in 83 patients with confirmed deep vein thrombosis. Blood 72:601-605

34. Barrett AJ $1981 \alpha_{2}$-Macroglobulin. Methods Enzymol 80:737-754

35. Meijers JC, Tijburg PN, Bouma BN 1987 Inhibition of human blood coagulation factor Xa by $\alpha_{2}$-macroglobulin. Biochemistry 26:5932-5937

36. Schmidt B, Mitchell L, Ofosu FA, Andrew M 1989 Alpha-2-macroglobulin is an important progressive inhibitor of thrombin in neonatal and infant plasma. Thromb Haemost 62:1074-1077 